\title{
LETTER
}

\section{The Swiss bus accident on 13 March 2012: lessons for pre-hospital care}

\author{
Urs Pietsch* \\ See related commentary by Lyon and Sanders et al., http://ccforum.com/content/16/4/138
}

Helicopter emergency medical services (HEMS) are a limited and expensive resource, and their possible effect on outcomes for trauma patients remains a subject of debate [1]. Last March, when a bus carrying 52 people, including 46 children, collided with a tunnel wall, Switzerland was fortunate to have such a well-organized HEMS system. The response to the accident proved that this system can provide a number of physician-staffed helicopters to a scene quickly (in less than 60 minutes) and at night.

This response was the topic of an article by Lyon and Sanders [2] in a recent issue of Critical Care, which I read with great interest. As a member of one of the first HEMS crews on the scene, I would like to add some significant details.

The article stated that eight helicopters arrived on the scene and flew the most badly injured children directly to university hospitals. Actually, there were initially seven helicopters on the scene: four from Air Zermatt, two from Air-Glaciers, and one from the Rettungsflugwacht/ Garde Aérienne (REGA). There was just one direct flight of a severely injured girl to a university hospital after she had received pre-hospital anesthesia. The majority of flights were short transports to a nearby hospital. Only later did a helicopter provide a relocation of one patient to a university hospital.

I would like to add some general information about the Swiss HEMS. The REGA covers the greater part of Switzerland. However, one area not covered by the REGA is the canton of Valais, in which the accident took place. In this canton, HEMS is provided by two air rescue services (Air Zermatt and Air-Glaciers), which provided the majority of rescue flights in this accident. Although the rescue system is regulated independently by each canton, the response to this accident showed how smoothly the different rescue organizations work together when necessary.

\section{Author's response}

Richard M Lyon

We thank the author for these important and informative comments, which provide further detailed insights into this tragic accident. Our original commentary was based on openly available information, and these additional first-hand clarifications serve to provide further details and lessons for other pre-hospital care providers. Again, the Swiss response to this incident was impressive and commendable.

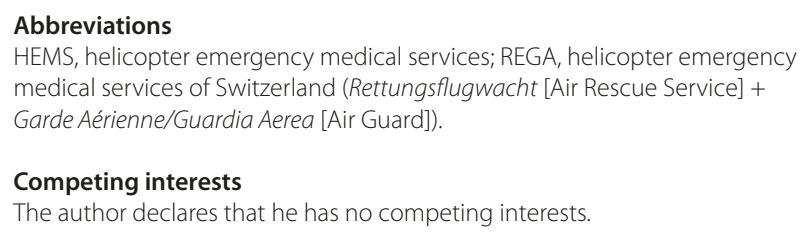

\section{Published: 27 February 2013}

\section{References}

1. Galvagno SM Jr, Haut ER, Zafar SN, Milin MG, Efron DT, Koenig GJ Jr, Baker SP, Bowman SM, Pronovost PJ, Haider AH: Association between helicopter vs ground emergency medical services and survival for adults with major trauma. JAMA 2012, 18:307.

2. Lyon RM, Sanders J: The Swiss bus accident on 13 March 2012: lessons for pre-hospital care. Crit Care 2012, 16:138. doi:10.1186/cc12489

Cite this article as: Pietsch U: The Swiss bus accident on 13 March 2012: lessons for pre-hospital care. Critical Care 2013, 17:416. 